\title{
Dr. Robert Brockelesby Davis
}

\author{
Sphurti Pusukuri \\ Postgraduate, Dept. of Psychiatry, Prathima Institute of Medical Sciences, Karimnagar, Telangana, India
}

*Corresponding Author: Sphurti Pusukuri

Email: sphurti.psi@gmail.com

\begin{abstract}
Dr. Robert B. Davis was one of the eminent figures shaping the field of Psychiatry in India. He was one of the founding member of the Indian Psychiatric Society and served as the president. He drafted the first proposal of the Mental Health Act of India along with other eminent psychiatrists in 1949. He served as the Superintendent and developed the European Mental Hospital (now known as the Central Institute of Psychiatry) in Ranchi into a leading centre for Psychiatry in India. He started the Kishore Nursing Home (now known as the Davis Institute of Neuropsychiatry) along with his wife. He was a passionate postgraduate teacher and a pioneer for introduction of several significant treatment procedures in India. He was awarded the Padma Shree in 1966 for his contributions to the field.
\end{abstract}

\section{Introduction}

Dr. Robert Brockelesby Davis comes from a family of doctors, academicians and missionaries in England. He is regarded as a pioneer in the field of Psychiatry. He made significant contributions in various aspects to Psychiatry in India. He held prominent positions in various institutions and received many awards in his professional career. ${ }^{1}$

\section{Early Life}

He was born on $27^{\text {th }}$ December 1911 in Amritsar, Punjab to Dr. George Brockelesby Davis and Lucy Gertrude Howard. He was the eldest of eight siblings. His father was an English doctor stationed in India as the chief surgeon in a missionary hospital in Amritsar and his mother was a missionary school teacher. His family had to relocate, when he was eight years old from Amritsar to Ely, a small village near Cambridge due to the growing Anti British movement in India. ${ }^{2}$

\section{Education}

He attended Stowe, a public school. He completed his B.A. in 1932 with anatomy, physiology and psychology (premedical training) from Cambridge and clinical training in a London hospital. In 1936, he got his MBBS degree from Cambridge with medals in Medicine and Surgery. He obtained his DPM degree by working in the Maudsley Hospital and Institute of Neurology, London whilst taking regular breaks from his work in Ranchi. ${ }^{2}$

\section{Personal Life}

He was married to Aleyamma Eapen in 1955, a Malayali Nurse who was the matron of the European Hospital. She was the first Indian nurse to be sent to the Maudsley Hospital for training in psychiatric nursing. He was earlier married to Ethel Amelia Tuffen and Eve Davis. ${ }^{1}$

He chose to become citizen of India in 1948 and was a great admirer of Gandhi. He passed away on the $8^{\text {th }}$ of October 1980 at the age of 69 with a fatal heart attack in Virginia when he was visiting his sister. ${ }^{2}$

\section{Professional Life}

In 1937, he joined the Indian Medical Service, was posted to Rawalpindi and because of his interest in Psychiatry he was appointed as a Psychiatric Specialist to the Northern Command from 1938-1942. He worked as a medical officer in-charge of a parachute brigade during the second world war in the British Indian Army. ${ }^{2}$

In 1946, Dr Robert B Davis was appointed as the Medical Superintendent to European Mental Hospital in Ranchi, now known as the Central Institute of Psychiatry. The hospital changed its name twice during his tenure: As Inter-provincial hospital in 1948 and subsequently to Hospital for Mental Diseases in 1952. During his time, he made the hospital into a leading centre for Psychiatry in India. $^{3}$

In 1955, he resigned from European Mental Hospital. He started the Kishore Nursing Home (now known as the Davis Institute of Neuropsychiatry) named after his friend Maharaj Kumar Raj Kishore Shahdeo along with his wife, which eventually became one of the reputed private psychiatric hospital in the country. ${ }^{2}$

\section{Significant Contributions}

In 1946, Dr. Nagendra Nath De consulted Major R. B. Davis and Brigadier Thomas Arthur Munro, Advisor in Psychiatry to the Indian Army and decided to revive the Indian division of the Royal Medico Psychological Association. Due to their efforts, the Indian Psychiatric Society was inaugurated in 1947. He first became it's secretary and then was elected as the President in $1954 .{ }^{4} \mathrm{He}$ regularly used to attend many national and international conferences and was a member of many international bodies.

The first draft of the Bill that subsequently became the Mental Health Act of India (1987) was written at C.I.P, Ranchi in 1949 by Dr R.B. Davis, then Medical Superintendent of CIP, S.A. Hasib, from Indian Mental Hospital, Ranchi and J Roy, from Mental Hospital, Nagpur. 
Dr Davis was also a member of the Union Public Service Commission for many years. ${ }^{5}$

Among the many significant contributions to psychiatry in India, he was the first one to use EEG and performed the first neurosurgery in Ranchi, along with army surgeons from the Namkom Military Hospital. He also started doing the first modified Electroconvulsive Therapy and Insulin Coma treatment in India. Whenever new drugs were made available in India, he used to conduct drug trails to know how they work in our population. A pathology lab and radiology department were started at European Mental Hospital, Ranchi during his tenure. ${ }^{2}$

He modernized the hospital trying to make it into a therapeutic community. He was passionate about teaching and taught his post-graduate students in Psychiatry. He trained many of the leading psychiatrists in India and also arranged a visit for some of the eminent psychiatrists in the world to visit Ranchi. ${ }^{2}$

\section{Areas of Interest}

His areas of research interests were the epidemiology of psychiatric disorders like schizophrenia, major depression, catatonia, and cannabis psychosis. ${ }^{2}$

Dr. Davis was also interested in other areas apart from psychiatry. He founded the Rotary club of Ranchi and became the first president. He was also a member of the Ranchi Chapter of the Masonic Lodge. He used to visit Kolkata every week to see patients and took part in the foundation of Antara and Asha Niketan. He was very interested in gardening, farming, English literature, Western Classical Music and almost anything else that he came across. He could speak various languages like English, French, Hindi, Bengali and Urdu. ${ }^{1}$

He was a member of Rose Society and had a keen interest in agriculture and experimented with growing different varieties of rice. ${ }^{1}$

\section{Awards}

He was given the Distinguished Service Order (D.S.O) by Queen Elizabeth for leading an evacuation of wounded soldiers in Nagaland. ${ }^{1}$

He was awarded the Padma Shree by President Radhakrishnan in 1966 for his contribution to the field of psychiatry in India. ${ }^{1}$

\section{Conclusion}

Throughout his career, Dr. Robert B. Davis paved the way for several changes in the practice of Psychiatry. His introduction of various treatment methods changed the department extensively during his tenure in Central Institute of Psychiatry, Ranchi. He showed great interest in teaching his postgraduates and was always an inspiration for them. He was one among the founders of the Indian Psychiatric Association and served as it's president. He was also an important member of the committee which drafted the bill for the Mental Health Act in 1949. He was honoured with the prestigious Padma Shree award in 1966 for his significant contributions to the field of Psychiatry.
Even today, his enormous contributions and zeal to advance the field serves to inspire many young Psychiatrists throughout the world.

\section{Acknowledgments}

Nil.

\section{Conflicts of Interest}

Nil.

\section{Sources of Funding}

Nil.

\section{References}

1. History of Davis Institute of Neuropsychiatry.[online] Available at: $<$ https://www.davisranchi.com/history.html $>$ [Last accessed on April 8,2020]

2. Davis E. Dr. Robert Brockelesby Davis (1911-1980). Indian J Psychiatry. 2010;52:137.

3. Aich TK, Das B, Bhat TS. Central Institute of Psychiatry: A fictional journey to past in a time machine. Indian $J$ Psychiatry. 2018;60(Suppl 2):S288-S94.

4. Nizamie SH, Goyal N, Haq MZ, Akhtar S. Central Institute of Psychiatry: A tradition in excellence. Indian J Psychiatry. 2008;50:144-8

5. Nizamie HS, Goyal N. History of psychiatry in India. Indian $J$ Psychiatry. 2010;52(Suppl S3):7-12.

How to cite this article: Pusukuri S. Dr. Robert Brockelesby Davis. Telangana J Psychiatry. 2020;6(1):945. 